\title{
NEGRITUDE: UMA IDENTIDADE LEGAL EM CONSEQUÊNCIA DA LIBERDADE
}

DE LA FUENTE, Alejandro; GROSS, Ariela. Becoming Free, Becoming Black: Race, Freedom, and Law in Cuba, Virginia and Louisiana. Nova York: Cambridge University Press, 2020. 281 p.

C

onquistar a liberdade sempre foi o objetivo das pessoas escravizadas nas Américas. Em todas as sociedades escravistas do continente mulheres e homens negros desenvolveram estratégias que, de alguma maneira, acabaram refletidas nos sistemas legais das colônias e nações onde viviam. As respostas das elites senhoriais às tentativas de alforria orientavam as leis, que acabaram constituindo critérios para uma cidadania de poucos, além de concessões e suspensão de direitos, ao mesmo tempo em que produziam hierarquias raciais. Alejandro de La Fuente e Ariela Gross afirmam que o livro que escreveram é um exercício de comparação que trata da ação de pessoas escravizadas e libertas sob os regimes escravistas nos estados de Luisiana e Virgínia, nos Estados Unidos, e em Cuba.

Fruto de uma pesquisa historiográfica transnacional, o objetivo da obra é mostrar o jogo de forças de elites escravistas que tentaram tornar sinônima a condição de negro e de escravizado. Do outro lado desse jogo, pessoas já libertas tensionavam a sociedade para, além da liberdade, adquirirem direitos, terem o reconhecimento de sua cidadania (mesmo quando não prevista em lei) e ainda ampliarem o número de libertas e libertos: amantes, familiares, amigos e outros membros da comunidade. As leis, objeto principal de análise, criavam as condições para se adquirir a liberdade. Os limites impostos 
ao exercício da vida pós-alforria produziam sistemas raciais desiguais, nos quais o negro, cada vez mais associado ao escravo, sofria restrições baseadas na "raça". Esse padrão orientou as sociedades escravistas, nas quais suas elites elegeram o "ser branco" como a condição necessária de cidadania, acesso a direitos e liberdade de movimento, o que variava de um lugar para outro. Criando jurisprudência, elaborando novos argumentos, inventando regras que desafiavam o direito ibérico ou o inglês e estadunidense, pessoas libertas também produziram categorias raciais que confrontavam a rigidez das leis.

Identidades raciais indefinidas e intermediárias foram inventadas por essas pessoas e existiram em diversas partes das Américas, assim também em Cuba, Luisiana e Virgínia. Tomando conjunturas políticas e espaços distintos, Gross e de La Fuente escolheram essas três sociedades escravistas para "desafiar percepções tradicionais da existência de um contraste entre um sistema racial fluido na América Latina, que reconhecia o escravo como pessoa, e um severo sistema binário nas colônias britânicas, que via o escravo unicamente como propriedade” (p. 5).

Aqui está uma das principais conclusões da obra: a maior ou menor facilidade para a obtenção da alforria e a consequente maior ou menor inserção dos libertos nas diferentes sociedades analisadas resultaram do quão bem sucedidas foram as elites de cada lugar em conectar a escravidão à pessoa negra e a cidadania à pessoa branca, bem como da capacidade da comunidade liberta em tirar proveito dos sistemas legais. Se na Virgínia e na Luisiana do século XIX, para se ter acesso a direitos, era preciso provar “não ser negro”, em Cuba isso já não era necessário. Cidadania, a despeito das tentativas em contrário das elites, não era prerrogativa dos brancos na sociedade escravista cubana. Além de ser resultado da agência da comunidade liberta, a alforria foi também fruto das brechas abertas pelo direito ibérico, sendo a maior delas a possibilidade de compra da liberdade, desde que aprovada pelo senhor, que também não tinha impedimento legal para alforriar gratuitamente.

Para os Estados Unidos, seguindo uma bem consolidada tradição na 
História e na Sociologia, poderíamos acreditar numa sociedade que desde o período colonial se distinguiria das latino-americanas pela rigidez de seu sistema racial. Contudo, aqui reside outra grande contribuição da obra: de forma muito sofisticada, o trabalho demonstra como o direito anglo-americano, diferente do ibérico, durante os primeiros anos do período colonial, demorou algum tempo para se adequar às especificidades de uma sociedade escravista e ao protagonismo de pessoas negras. Uma vez que os primeiros africanos chegaram naquele país somente nas primeiras décadas do século XVII, isso permitiu que também na Virgínia, assim como em Cuba, africanos e os primeiros afroamericanos libertos tivessem condições de tentar, e às vezes conquistar, a alforria por meio de diversos métodos.

$\mathrm{O}$ autor e a autora afirmam ter escolhido a Virgínia e a Luisiana para dar ênfase ao processo de transição, dentro do mesmo país, de um sistema escravista e racial mais flexível para outro mais rígido, que se distinguiria do cubano, enquanto o anterior seria semelhante. De La Fuente e Gross afirmam voltar para questões comparativas clássicas sobre os regimes raciais e escravistas dessas regiões para analisá-las, do ponto de vista de suas tradições legais, mas também das suas práticas culturais e sociais, para entender as estratégias pessoais dos escravizados que desafiaram esses sistemas legais.

No capítulo 1, o livro mostra que, ainda no início do período colonial, entre 1500 e 1700 , as três sociedades começaram a construir sistemas legais que tinham por objetivo consolidar as pessoas negras como excluídas, gradativamente e de maneiras diferentes, da vida pública. Em Cuba colonial, Luisiana e Virgínia, as elites escravistas guardaram para si os privilégios da vida livre e cidadã. Mas isso não aconteceu ao mesmo tempo nas três localidades. Contrariando a noção de um sistema racial fluido na América Latina, nos primeiros anos do século XVI, em Cuba, as leis refletiam o projeto de relegar libertos e libertas a um lugar social subalterno, devido à cor da sua pele, marcada pela escravidão. Contudo, esse era um momento de uma comunidade liberta ainda incipiente, que lutava contra um sistema legal de longa tradição escravista, o sistema romano que inspirou o ibérico. 
Esse mesmo código de leis, o romano, também estimulou a confecção dos Códigos Negros (Codes Noirs) dos franceses, que chegaram à Luisiana no início do século XVIII.

Assim, antes de a Luisiana fazer parte da federação estadunidense, a forma como a legislação estava produzindo hierarquias raciais mais se assemelhava ao que acontecia em Cuba. Enquanto isso, na Virgínia do início do século XVII, africanos recémchegados podiam acumular bens, processar pessoas brancas, possuir escravos e se engajarem em relações amorosas interraciais. Contudo, depois da segunda metade do século XVII, as ideias de pureza de sangue, degradação racial e segregação já estavam ganhando força na Virgínia, que paulatinamente começou a implementar, os mesmos códigos de regramento e hierarquias raciais vigentes em outras sociedades escravistas desde um século antes.

Além de inventar "o branco" como ideal de cidadão, os sistemas legais de Cuba, Luisiana e Virgínia, necessariamente, inventaram categorias raciais como "o negro", "o mulato" e "o pardo" como símbolos de degradação, desonra e, obviamente, escravidão. Esses sistemas legais não produziram essas leis isoladamente. Havia uma percepção mais ampla - e em diferentes regiões - das elites e senhores de escravos sobre os impactos desse ou daquele regramento legal. As pessoas escravizadas e libertas, que também circulavam pelo Atlântico, traziam suas próprias interpretações das leis de onde quer que estivessem. Códigos escravistas que visavam aproximar a condição de libertos dos escravizados existiram desde o século XVI em Cuba, no final do século XVII nas colônias francesas do Caribe, inclusive na Luisiana, e na Virgínia, já em 1691, através dos Black Codes.

Na Virgínia, durante as primeiras décadas do século XVII, o "lugar intermediário" atribuído a homens e mulheres de identidade racial ambígua (mestiços) serviu como argumento para a liberdade e também para autorizar a legalização de casamentos inter-raciais, sob a justificativa de que pelo menos um dos nubentes era descendente de indígenas, ou meio indígena, quase branco, ou meio negro ou não totalmente negro. Essa realidade mudou com o tempo 
perdendo gradativamente essas pessoas direitos reconhecidos pela lei, o que enfraqueceria a comunidade de negros livres e libertos. Em Cuba, onde a liberdade não necessariamente era uma prerrogativa restrita às pessoas brancas, ainda que impondo restrições e hierarquias legais que os distinguiam dos brancos, as pessoas de cor continuaram até a abolição a desfrutar da inserção social em diversos setores da sociedade: militar, religioso, político. Isso produziu uma comunidade liberta numerosa e influente, o que foi possível pela possibilidade da compra da alforria, que era um direito previsto em lei, embora condicionado à concordância dos senhores.

O capítulo 2 dá ênfase a essas práticas de pessoas escravizadas e libertas que construíram caminhos para a liberdade nos séculos XVI e XVII. Enquanto as elites escravistas fortaleciam através das leis a noção que associava descendência africana a cativeiro, mulheres e homens escravizados e libertos buscavam nas entrelinhas e nas imprecisões dos textos legais formas de reclamar direitos. Mulatos, pardos e mestiços eram identidades reinvidicadas, pois, ainda que não pudessem desfrutar da cidadania em sua plenitude, podiam garantir uma “meia-cidadania”, pois sempre havia a esperança de torná-la plena.

No caso dos processos judiciais nos quais as pessoas reivindicavam a liberdade, fosse por terem nascido de ventre indígena, fosse por terem nascido de uma mulher branca livre, o precedente da liberdade aberto pelas pessoas "mestiças" fez com que o sexo inter-racial fosse proibido e se tornasse alvo de perseguição legal em Cuba, embora sem sucesso. Já na Luisiana e na Virgínia essa proibição aconteceu de forma mais impactante e bem sucedida. Em Cuba, argumentam autora e autor, o fato de a negociação da alforria ser um acordo entre senhor e escravizado, a liberdade terminava gerando uma relação de submissão e controle do liberto, não ameaçando o sistema escravista.

Como bem lembram de La Fuente e Gross, no século XVIII, em Cuba, a autocompra já representava $80 \%$ das manumissões, a maioria beneficiando mulheres. A compra da liberdade, que podia ser feita através de arranjos diversificados, também criou novas situações legais que, muitas vezes, pela habilidade da comunidade liberta, transformaram-se em direitos, como 
era o caso da coartação, espécie de alforria paga a prazo. Reflexo desse processo era a comunidade liberta que se formou na sociedade cubana, onde a alforria instituía o direito de viver em liberdade, morar e circular onde quisesse, celebrar contratos, possuir propriedade, inclusive outros escravos, e assim por diante.

Essas possibilidades não existiam da mesma maneira na Luisiana do século XVIII e na Virgínia do mesmo período, onde as chances de comprar a alforria, principal meio de adquirir a liberdade, eram bem mais restritas. O Code Noir da Luisiana, sob o domínio francês, datado de 1724, restringia muito as possibilidades de compra da liberdade. A partir de 1803, quando o território foi comprado pelos EUA, a situação passou a se assemelhar à do estado da Virgínia, onde, no século XVII, ainda não havia regramento legal específico a respeito das manumissões. Entre 1705 e 1782, a legislação colonial da Virgínia não só começou a proibir a compra da alforria, mas também a reduzir direitos, a implementar medidas que aproximavam a condição de vida dos libertos das pessoas escravizadas, inclusive a proibição dos casamentos inter-raciais.

A noção da liberdade como um direito universal, algo bastante debatido na Era das Revoluções Atlânticas, é o tema do capítulo 3. Após a independência dos Estados Unidos, em 1776, do Haiti, em 1804, e do sem número de revoltas escravas ocorridas nas Américas, sobretudo no Caribe, ampliou-se a noção de direito à liberdade e à cidadania. Paralelamente, como frisam o autor e a autora, esse também seria o momento de expansão da escravidão e do endurecimento das leis de acesso à liberdade na Virgínia e posteriormente na Luisiana. Como resultado da Revolução Haitiana, grande imigração para Cuba aumentou ali a população de cor, que dobrou entre junho e dezembro de 1803, apesar de leis que restringiam essa imigração, que era vista em todas as Américas como propagadora de ideias revolucionárias. Por esse motivo esses imigrantes foram deportados da ilha espanhola em 1809, e boa parte deles seguiu para Nova Orleans, o que fez com que a população de cor na capital de Luisiana triplicasse, chegando a 63\% do total em 1810. 
Essa onda migratória de pessoas de cor livres e escravizadas (estas levadas por seus senhores), vindas do Haiti para Cuba e Nova Orleans, se somaria à já densa população de cor livre e liberta residente nesses locais. A Virgínia não estava entre os destinos dos haitianos porque havia proibido esses imigrantes indesejados. A questão que preocupava as elites escravistas era o efeito da liberdade, ao suscitar aspirações de cidadania e inclusão na comunidade liberta e livre, em uma população cada vez mais ansiosa por direitos. Tanto em Havana quanto em Nova Orleans e Richmond, capital da Virgínia, a resposta a essas pretensões vinha através de regramentos legais que limitavam ainda mais os direitos da população de cor e, gradativamente, reduziam as possibilidades de alcançar a alforria, paga ou gratuita. Em 1806, na Virgínia, uma lei passou a exigir que pessoas libertas deixassem o Estado. Na Luisiana, onde durante o domínio espanhol (1763 e 1800) se percebeu um crescente número de alforrias, com a compra do território pelos estadunidenses, em 1803, as leis que facilitavam a alforria foram banidas pelo Black Code de 1806.
Em Cuba e na Luisiana, esta durante o domínio espanhol, a alforria, sobretudo quando concedida pelos senhores, não era vista como ameaça à estrutura social e econômica escravista. Já na Virgínia, no final do século XVIII e primeiros anos do século XIX, o debate sobre a alforria esteve na esteira de um debate mais amplo sobre nação, direitos e cidadania que apontava para a exclusão dos negros. Enquanto os ideais abolicionistas prosperavam timidamente no Norte, eles eram muito mal vistos entre senhores de escravos e legisladores da região Sul dos Estados Unidos, onde ficava a Virgínia, para quem todas as leis relativas à manumissão pareciam ameaçadoras. Uma lei aprovada em 1806 previa que os libertos que permanecessem no estado seriam reescravizados. Leis dessa natureza não foram implementadas em Cuba ou na Luisiana espanhola, que a despeito de promoverem regras legais que colocavam brancos, escravizados, negros, pardos e libertos em condições sociais e legais distintas, entendiam que a comunidade liberta era parte da sociedade, como resultado da própria escravidão. 
Gross e La Fuente informam que em Cuba, negros e mulatos livres compunham 38\% da população não branca e $20 \%$ da população como um todo em 1792. Estava na cidade de Havana a maior concentração de pessoas registradas como "negras" e "mulatas" na condição de livres, que compunham 19\% da população da cidade, ocupando cargos em irmandades religiosas e atuando como militares e membros do governo municipal. Na Luisiana, especificamente em Nova Orleans, a população liberta aumentou significativamente durante o domínio espanhol, de 3\% em 1771 para 14\% em 1806. Esse perfil demográfico fez com que essa região ganhasse uma característica muito própria em relação ao restante dos Estados Unidos, até sua incorporação ao país em 1803.

O fato é que no início do século XIX a condição dos libertos na Luisiana se assemelhava mais à de Cuba que à da Virgínia, e se os mulatos não eram presumidamente considerados pessoas escravizadas nessas duas regiões, o eram sob as leis de Richmond. O século XIX protagoniza dois acontecimentos concomitantes nas três sociedades: ao passo que houve um aumento no número de alforrias, também aconteceu uma expansão da escravidão na Virgínia e Luisiana. Nessas duas últimas regiões, os legisladores conseguiram estrangular novas possibilidades de alforria sobretudo na década de 1850 .

O capítulo 4 discute o período entre 1830 e 1860, quando as revoltas, o movimento abolicionista e o crescimento da população liberta nas três regiões fizeram com que ganhassem força as propostas de expulsão dos membros dessa parcela da sociedade, justificadas pela ideia de que os libertos eram estrangeiros, outsiders, anomalias criadas pela escravidão.

As propostas de deportação dos negros livres e libertos foram apresentadas na Luisiana, em 1850, e também na Virgínia, anos antes, após a publicação do panfleto Appeal to the Colored Citizens of the World (1829), escrito pelo abolicionista negro David Walker, no qual ele defendia ideais considerados radicais, como a abolição imediata da escravidão e a cidadania para as pessoas libertas e os negros já livres. A revolta de Nat Turner, ocorrida em 1831, também acendeu o alerta, uma vez que se temeu que os libertos pudessem apoiar pessoas 
escravizadas como Turner na organização de revoltas escravas. Tanto a revolta de Turner quanto o panfleto de Walker já marcavam um novo momento de organização da comunidade liberta, que agora, diferente de iniciativas individuais, faziam coro à demanda do movimento abolicionista, que pregava, além de liberdade, direitos para os negros semelhantes aos que tinha a população branca. $\mathrm{Na}$ Luisiana e na Virgínia, leis severas passaram a punir com prisão, castigos físicos e até a reescravização (no caso dos libertos) quem fosse encontrado com panfletos como o de Walker ou quem defendesse a pauta abolicionista.

Em Cuba, a revolta conhecida como La Escalera (1844) suscitou nos senhores de escravos receio sobre os perigos de uma união entre escravizados e livres de cor, sobretudo aqueles que compunham as elites de cor. $\mathrm{Na}$ década de 1840 também se discutiu expulsar os libertos da ilha, mas no final das contas, a lei se restringiu aos emancipados, que eram os africanos recém-chegados através do tráfico ilegal. Segundo La Fuente e Gross, isso indica mais uma particularidade da escravidão em Cuba na comparação com a Virgínia e a Luisiana: ao mesmo tempo em que compartilhavam com senhores de escravos estadunidenses a ideia de que africanos só deveriam permanecer no território como escravos, a ideia de "não pertencimento dos libertos à nação” não se aplicava àquela maioria que já vivia na ilha. A participação social e a quantidade de pessoas libertas na sociedade cubana, naquela altura, fazia com que a deportação fosse algo impensado. Enquanto isso, nos Estados Unidos, tornava-se incompatível com as ideias de nação a presença de pessoas negras na sociedade na mesma condição que as pessoas brancas, como livres e quiçá como cidadãs.

Enquanto em Cuba, em 1860, $62 \%$ da população negra era escravizada, na Luisiana, no mesmo período, os cativos representavam 95\% dos negros, e na Virgínia 89\%. Tais números reforçam mais uma vez a tese do livro: enquanto as possibilidades de aquisição da liberdade cresceram em Cuba ao longo do século XIX, na Virgínia e na Luisiana, no mesmo período, as leis antialforria se tornaram mais restritivas e opressivas, o que reduziu a proporção de livres de cor na população, e portanto a possibilidade de se formar uma comunidade 
livre negra ampla e influente no Sul dos Estados Unidos.

Vejamos como isso impactou estratégias corriqueiras da comunidade negra na Virgínia. Em 1832, à população de cor só era permitido comprar para si pessoas da mesma família, mas anos mais tarde, em 1858, ela foi completamente proibida de comprar escravos, fossem seus familiares ou não. Na Luisiana, a possibilidade da compra da alforria foi banida legalmente em 1857, e a reescravização de quem desobedecesse à determinação de sair do estado foi implementada em 1859.

A despeito do ambiente menos hostil em Cuba, existiam leis de controle dos libertos. As elites escravocratas da ilha estavam atentas ao que ocorria nos EUA às vésperas da Guerra Civil e viam com bons olhos os interesses dos escravistas de lá de ampliarem seu território, anexando Cuba. Contudo, a tendência observada na sociedade escravista sulista de suspender direitos já adquiridos da comunidade liberta era vista como uma manobra perigosa. Ao contrário dos Estados Unidos, em Cuba não existiam teses científicas e religiosas em defesa da escravidão.
Além disso, na sociedade cubana, a presença dos libertos acabou sendo algo compatível com a sociedade escravista. Em 1860, possuindo uma população liberta três vezes maior que a da Luisiana e quatro vezes maior que a da Virgínia, a liberdade negra em Cuba não era vista como uma anomalia ou um absurdo legal, muito menos como um perigo à estabilidade do sistema.

As diferenças a respeito da forma como as três regiões administraram e legalizaram as hierarquias raciais, nas décadas de 1850 e 1860, são discutidas no quinto e último capítulo. Foi nesse período que, segundo o autor e a autora, enquanto as elites brancas cubanas já estariam familiarizadas em conviver com uma população de cor liberta majoritária, criando estratégias mais fluidas de hierarquização social com base na raça, o Sul dos Estados Unidos vivenciaria um processo distinto. Naquele período, as elites escravistas fortaleceram seus argumentos em defesa do cativeiro como resposta ao movimento abolicionista, com base na ideia de que a cidadania era branca e a escravidão seria a condição natural para as pessoas negras. Nesse momento o livro resgata o papel do 
racismo científico para demonstrar como a ideia de supremacia branca, que era vista com simpatia, inclusive por homens brancos pobres e imigrantes, foi utilizada pelos legisladores para gradativamente impossibilitar de vez as alforrias e outros direitos das pessoas negras.

Quando na Virgínia e na Luisiana ecoavam os anúncios da Guerra Civil, pessoas negras de todos os tons de pele e origens, escravizadas ou libertas, já estavam exiladas da vida pública, das instituições, já eram proibidas de possuir bens, inclusive escravos, e também de conviverem nos espaços públicos com pessoas brancas. A ambiguidade racial deixou de ser estratégia admitida legalmente para o reconhecimento da liberdade. Outros meios comuns utilizados para a ascensão social, como a educação, também foram barrados. Na Virgínia e na Luisiana foram proibidas as escolas e as iniciativas de letramento do negro. Em Cuba, o letramento era permitido, mas as escolas eram segregadas e, portanto, o acesso à educação dos libertos era escasso e desigual, mas legalmente possível.

Ainda no caso do reconhecimento da branquitude (whiteness) ou da ambiguidade racial de alguém (mestiçagem), na Virgínia a experiência de uma vida livre e o reconhecimento da comunidade eram critérios fundamentais para uma pessoa que quisesse provar judicialmente o mérito da sua liberdade. Alguns eram sinais necessários para um homem ser reconhecido como branco: ser eleitor, fazer parte de um júri, ocupar cargo público, fazer parte de uma organização militar e ser casado com uma mulher branca. Essas "provas de branquitude" ou de não negritude mudavam de acordo com o gênero, e no caso das mulheres, os processos de liberdade analisados revelam os seguintes critérios: beleza, recato sexual e caráter moral.

Para enfatizar as diferenças entre a legislação da ilha do Caribe e o Sul estadunidense, La Fuente e Gross nos informam que nenhum desses critérios era exigido em Cuba em um processo de liberdade ou de reconhecimento de algum direito. $\mathrm{Na}$ ilha, também, os "casamentos desiguais" não eram considerados relações entre pessoas não equivalentes, uma vez que a sociedade reconhecia outras diferenças como a de classe, que assim como a ocupação profissional, também informava 
sobre raça. Atividades manuais como alfaiate, pintor e escultor eram de homens negros, e os brancos que as exercessem carregavam a marca do desprestígio. Portanto, casamentos entre pessoas negras e brancas pobres não representavam uma transgressão, embora, concomitantemente, como já dito, nessa mesma sociedade as hierarquias raciais e a noção de negros serem inferiores aos brancos também existissem. Nos Estados Unidos, autor e autora nos lembram que esse tipo de relações sempre existiu, mas era objeto de grande incômodo social e regulamentação legal. As relações entre mulheres brancas e homens negros, especialmente, eram alvo de grande perseguição, que justificavam atos violentos. Isso porque o corpo da mulher branca representava a tal pureza racial tão valorizada no país. Nos Estados Unidos pós-abolição, o branco consolidou-se como identidade da nação, entrando o século $\mathrm{XX}$ e podemos afirmar que a ideia de supremacia branca embala projetos antidemocráticos naquele país até hoje.

Becoming Free, Becoming Black oferece uma grande contribuição à historiografia da escravidão nas
Américas por diversos motivos. Fruto de uma extensa pesquisa, o resultado não é somente um trabalho comparativo, mas também transnacional. Na obra fica bastante evidente que em Cuba, Virgínia e Luisiana, tanto pessoas brancas que elaboravam as leis e possuíam escravos, quanto as pessoas “de cor" que aspiravam por liberdade e direitos estavam atentas às estratégias e tradições legais empregadas em outras sociedades escravistas para atingir seus objetivos. Embora códigos de leis, processos e requerimentos de liberdade sejam fontes documentais já amplamente utilizadas pela historiografia da escravidão, a análise ganha contornos de novidade quando utilizadas para investigar o processo gradual de mudanças nessas sociedades, sobretudo na Luisiana, que transitou de uma tradição legal para outra, até se tornar parte dos Estados Unidos.

Já o peso do protagonismo das comunidades livres de cor no uso das leis fez com que as elites escravistas, em diversos momentos, adequassem seus interesses às ações ou possíveis reações daquelas comunidades. Assim, legisladores e senhores muitas vezes eram obrigados a encontrar 
um equilíbrio entre a manutenção do cativeiro e das hierarquias raciais com o reconhecimento dos direitos dos negros livres e libertos, evitando conflitos e até revoltas, sobretudo se isso significasse a temida união da "raça de cor". Esse era um temor das elites escravistas em todas as Américas, inclusive no Brasil, nação com a qual o livro nos permite traçar muitos paralelos, especialmente com o caso cubano.

Ademais, a obra nos faz pensar sobre raça e racialização nas sociedades escravistas, não só como um fenômeno do pós-abolição, mas como um projeto das elites escravistas de administração das diferenças nas sociedades multirraciais, tendo em vista um presente, mas também um futuro no qual teriam que conviver com pessoas negras livres. Esses processos criaram uma nova tradição legal, que no século XIX produziu categorias raciais levadas em consideração abertamente nos Estados Unidos, mas não em Cuba. O fato é que, de uma forma ou de outra, essas leis legitimaram o racismo e legalizaram diferenças. Nesse sentido, Becoming Free, Becoming Black representa uma importante contribuição para os debates sobre formação das estruturas raciais e do racismo na América Latina e nos Estados Unidos. Como podemos perceber pela leitura da obra, o racismo pode até ser fruto de um projeto antigo, mas nossas origens escravistas fazem com que ele não seja, de forma alguma, uma ideia e uma prática distantes. Racismo e noções de supremacia branca ainda orientam e justificam nossas desigualdades sociais, inclusive com o amparo de leis, ainda que de forma silenciosa.

\section{Luciana da Cruz Brito (D)}

Universidade Federal do Recôncavo da Bahia

doi: 10.9771/aa.v0i63.44020 